\title{
Multi-Criteria Decision Analysis Methods Comparison
}

\author{
Beate ZLAUGOTNE ${ }^{*}$, Lauma ZIHARE ${ }^{2}$, Lauma BALODE ${ }^{3}$, Antra KALNBALKITE ${ }^{4}$, \\ Aset KHABDULLIN ${ }^{5}$, Dagnija BLUMBERGA ${ }^{6}$ \\ ${ }^{1-4,}{ }^{6}$ Institute of Energy Systems and Environment, Riga Technical University, Azenes iela 12/1, \\ Riga, LV-1048, Latvia \\ ${ }^{5}$ Rudny Industrial Institute, 50 let Oktyabrya street 38, Rudny, 111500, Republic of Kazakhstan
}

\begin{abstract}
Multi-criteria decision analysis (MCDA) is widely used to solve various decision problems through alternative evaluation. MCDA methods can be used in every field that can define a problem, alternatives and criteria. However, finding the appropriate method can influence the results, in this research five MCDA methods have been tested on the renewable energy sector in Latvia to find the best alternative. The main results showed that TOPSIS, VIKOR and PROMETHEE-GAIA have similar priority selection and the highest ranking was selected for hydropower plant, but MULTIMOORA and COPRAS results were beneficial to Solar PV.
\end{abstract}

Keywords - COPRAS; MCDA; MULTIMOORA; PROMETHEE-GAIA; renewable energy; TOPSIS; VIKOR.

\section{INTRODUCTION}

Multi-criteria decision analysis (MCDA) is a multi-step process consisting of a set of methods to structure and formalise decision-making processes in a transparent and consistent manner [1]. Over the years, MCDA has developed many methods and software to resolve the defined problems. To use the methods, it is important to define the problem, alternatives, and criteria that may be different types of costs, environmental impact indicators, social indicators, energy efficiency, quality and other specific criteria that are relevant to the problem. When there are many alternatives for one problem, it is important to find the most suitable alternative with the best cost criteria, lowest impact on environment, and good energy efficiency. This can be achieved by using the MCDA method as a tool for comparing alternatives.

There are many methods that can be used for solving problems and they can be arranged according to different parameters. Each MCDA method has its own calculation method by which alternatives are queued and it is not possible to claim that using specific methods with the same input data will lead to the same final result. Methods can be selected by the type of result [2]. If the result is required as a comparison of values, AHP, MULTIMOORA, MAUT, Weighted Sum Method, Weighted Product Method and other methods can be used. Using AHP, TOPSIS, and VIKOR, COPRAS, STEP and other methods can be used to reach the defined goal and to find the best alternative from the provided options. PROMETHEE and ELECTRE methods are based on pairwise comparison and conformity assessment for the desired purpose.

* Corresponding author.

E-mail address: beate.zlaugotne@rtu.lv 
There is a possibility to get the same results using different methods: TOPSIS and VIKOR [3], VIKOR and PROMETHEE [4] methods lead to quite similar results, TOPSIS and COPRAS results are practically the same except for two alternatives [5], MULTIMOORA, TOPSIS and VIKOR [6], VIKOR, COPRAS and PROMETHEE [7], COPRAS and VIKOR [8] method lead to the same results. But there might be results that do not match, for example, VIKOR, COPRAS and TOPSIS results [9] and MULTIMOORA and PROMETHEE [10] ranking results.

There are many MCDA methods and each method has its own definition of best alternative and it is not determined if using same input data in different MCDA methods will give the same results. To see how similar or different results might evolve from five MCDA methods - a comparison of TOPSIS, VIKOR, COPRAS, MULTIMOORA, and PROMETHEE-GAIA methods are made, using data about renewable energy technologies alternatives in Latvia. The alternatives applied are solar photovoltaic (Solar PV), wind power plants (WPP), hydropower plants (HPP) and biomass, and biogas combined heat and power (CHP) (Bio-energy CHP). To compare the methods, seven criteria are used about cost, $\mathrm{CO}_{2}$ emissions and electrical capacity. After this comparison, it will be possible to see what results the MCDA methods provide, similar or different, and which renewable energy technologies are best for Latvia.

\section{METHODS}

MCDA methods can be selected by their properties and requirements. A summary of properties applies through the TOPSIS, VIKOR, COPRAS, MULTIMOORA, PROMETHEEGAIA and AHP methods to select the most appropriate method by data and ranking type, software, input and output data are provided in Table 1. This comparison was done to see similarities and differences between methods.

In the Analytical Hierarchy Process (AHP) method, alternatives are listed and then compared pairwise according to their contribution to reaching each objective or criterion [1]. This method was developed by Thomas L. Saaty and is one of the popular methods to find weight of criteria.

For all selected methods subjective data are criteria weights. The TOPSIS method requires minimal input data and results are easy to understand and it is with shortest geometrical distance to ideal result [2]. The VIKOR method focuses on alternative ranking by closeness to best solution and the maximum and minimum values of the criteria give impact to result [3]. COPRAS method takes into account performance of the alternatives with best and worst values which affect the result [4]. With MULTIMOORA method it is possible to determine the objectives of conflicting criteria and it has a ratio system and reference point calculation method [5]. PROMETHEE-GAIA method is based on the computation of preference degrees and it shows which alternative would be more appropriate to solve the problem and how criteria weight impact alternative position [2]. 
TABLE 1. SUMMARY OF MCDA METHODS

\begin{tabular}{|c|c|c|c|c|c|c|}
\hline & TOPSIS & VIKOR & COPRAS & MULTIMOORA & PROMETHEE-GAIA & AHP \\
\hline $\begin{array}{l}\text { Type of } \\
\text { normalization }\end{array}$ & $\begin{array}{l}\text { Vector normalisation } \\
\text { (square root of sum (L2 } \\
\text { normalization) }\end{array}$ & $\begin{array}{l}\text { Linear normalization } \\
\text { (L1 normalization) }\end{array}$ & $\begin{array}{l}\text { Vector } \\
\text { normalization } \\
\text { (sum) }\end{array}$ & $\begin{array}{l}\text { Vector normalization } \\
\text { (square root of sum) }\end{array}$ & $\begin{array}{l}\text { Normalization is } \\
\text { performed automatically }\end{array}$ & $\begin{array}{l}\text { Vector normalisation } \\
\text { (sum) }\end{array}$ \\
\hline Suitability & $\begin{array}{l}\text { Choice problems, ranking } \\
\text { problems }\end{array}$ & $\begin{array}{l}\text { Choice problems, } \\
\text { ranking problems }\end{array}$ & $\begin{array}{l}\text { Choice problems, } \\
\text { ranking problems }\end{array}$ & $\begin{array}{l}\text { Choice problems, } \\
\text { ranking problems }\end{array}$ & $\begin{array}{l}\text { Choice problems, ranking } \\
\text { problems, } \\
\text { description problems } \\
\text { (GAIA) }\end{array}$ & $\begin{array}{l}\text { Choice problems, ranking } \\
\text { problems, } \\
\text { sorting problems } \\
\text { (AHPsort) }\end{array}$ \\
\hline Inputs & $\begin{array}{l}\text { Ideal and anti-ideal option } \\
\text { weights }\end{array}$ & $\begin{array}{l}\text { Best and worst option } \\
\text { weights }\end{array}$ & $\begin{array}{l}\text { Best and worst } \\
\text { option } \\
\text { weights }\end{array}$ & $\begin{array}{l}\text { Best and worst option } \\
\text { weights }\end{array}$ & $\begin{array}{l}\text { Indifference and } \\
\text { preference thresholds } \\
\text { weights }\end{array}$ & $\begin{array}{l}\text { Pairwise comparison on } \\
\text { ratio scale }(1-9)\end{array}$ \\
\hline Outputs & $\begin{array}{l}\text { Complete ranking with } \\
\text { closeness score to ideal and } \\
\text { distance to anti-ideal }\end{array}$ & $\begin{array}{l}\text { Complete ranking with } \\
\text { closeness score to best } \\
\text { option }\end{array}$ & Complete ranking & Complete ranking & $\begin{array}{l}\text { Partial and complete } \\
\text { ranking (pairwise } \\
\text { outranking degrees) }\end{array}$ & $\begin{array}{l}\text { Complete ranking with } \\
\text { scores }\end{array}$ \\
\hline $\begin{array}{l}\text { Preference } \\
\text { function }\end{array}$ & $\begin{array}{l}\text { Distance metric (Euclidean } \\
\text { distance, Manhattan distance, } \\
\text { Tchebycheff distance) }\end{array}$ & $\begin{array}{l}\text { Distance metric } \\
\text { (Manhattan distance) }\end{array}$ & Min Max & Min Max & $\begin{array}{l}\text { Usual, Linear, U-shape, } \\
\text { V-shape, Level, Gaussian }\end{array}$ & \\
\hline Approach & Qualitative and/or quantitative & Quantitative & Quantitative & Quantitative & $\begin{array}{l}\text { Qualitative and/or } \\
\text { quantitative }\end{array}$ & Qualitative \\
\hline Ranking scale & 0 to 1 & Positive values & Positive values & Positive values & -1 to 1 & 0 to 1 \\
\hline $\begin{array}{l}\text { Best } \\
\text { alternative }\end{array}$ & Max value & Min value & Max value & Max value & Max value & Max value \\
\hline $\begin{array}{l}\text { Consistency } \\
\text { levels }\end{array}$ & no restrictions & no restrictions & no restrictions & no restrictions & $7 \pm 2$ & 9 \\
\hline Software & $\begin{array}{l}\text { MS Excel, Matlab, } \\
\text { Decerns }\end{array}$ & MS Excel & MS Excel & MS Excel & $\begin{array}{l}\text { Visual Promethee, } \\
\text { Decision Lab, } \\
\text { D-Sight, Smart Picker Pro }\end{array}$ & $\begin{array}{l}\text { MS Excel, } \\
\text { MakeItRational, } \\
\text { ExpertChoice, Decision } \\
\text { Lens, HIPRE 3+, } \\
\text { RightChoiceDSS, } \\
\text { Criterium, EasyMind, } \\
\text { Questfox, ChoiceResults, } \\
\text { 123AHP, DECERNS }\end{array}$ \\
\hline
\end{tabular}




\subsection{INPUT DATA}

Input data - criteria with values and alternatives - have been taken from 'Progress in renewable energy technologies: innovation potential in Latvia' [6] and are presented in Table 2. These data are used to find the best alternative for renewable energy production. In each method, data are the most important element to rank alternatives because these values are used in the calculation process.

TABLE 2. INPUT DATA

\begin{tabular}{llllll}
\hline \multirow{2}{*}{ Criteria } & \multicolumn{2}{l}{ Alternatives } & & & \\
\cline { 3 - 6 } \cline { 3 - 5 } & Solar PV & WPP & HPP & Bio-energy CHP \\
\hline $\mathrm{C} 1$ & Installed electrical capacity, MW & 1 & 77 & 1565 & 155 \\
$\mathrm{C} 2$ & Investment cost, $€ / \mathrm{kW}$ & 1238 & 3565 & 1388 & 1113.5 \\
$\mathrm{C} 3$ & Operation and maintenance cost, $€ / \mathrm{kW}$ & 12.37 & 26.7 & 2.67 & 0.00446 \\
$\mathrm{C} 4$ & RES equipment prices by manufacturer, $€ / \mathrm{kW}$ & 430 & 1380 & 1290 & 3787.5 \\
$\mathrm{C} 5$ & Levelled cost of electricity, $€ / \mathrm{kW}$ & 0.08 & 0.06 & 0.09 & 0.075 \\
$\mathrm{C} 6$ & Life-cycle $\mathrm{CO}_{2}$ emissions, $\mathrm{gCO}_{2} \mathrm{eq} / \mathrm{kWh}$ & 200 & 150 & 150 & 200 \\
$\mathrm{C} 7$ & Job creation, thousands & 3095 & 1155 & 865 & 528 \\
\hline
\end{tabular}

Data about installed electrical capacity $(\mathrm{C} 1)$ shows maximum net production capacity of power plants in Latvia and are taken from the IRENA report on Renewable Capacity Statistics [7]. From Data for investment cost (C2) are from IRENA report on Renewable Power Generation Costs [8] and depend on alternative capacity and criteria levelled cost of electricity (C5) data which are average values for each alternative in Europe. The criteria operation and maintenance cost (C3) and RES equipment prices by manufacturer (C4) data are from the IRENA report on Renewable Power Generation Costs [8] and from Energy Outlook [9] and concern Europe. Life-cycle $\mathrm{CO}_{2}$ emissions (C6) data are on Europe and are from the European Environment Agency (EEA) report on Renewable energy in Europe-2017 [10] and World Nuclear Association report data [11]. Job creation (C7) criteria data are from the IRENA review on Renewable Energy and Jobs [12] and pertain to alternatives in Europe.

For some MCDA methods it is important to know if it is better for the value of the criteria to be maximizing or minimizing. In this study, most criteria values are better to be minimizing and only electrical capacity and job possibilities are better to be maximising.

\section{2. $A H P$}

In the AHP method an important indicator is the number of criteria and it affects result consistency because more than seven criteria lead to an increase in inconsistency [22].

The AHP model facilitates the organization of the various variables in levels of hierarchy and it helps experts to evaluate criterion against criterion [23].

The AHP method equations (1) and (2) are [22]:

- Define and value criteria (scale 1-9).

- Calculate normalized matrix using Eq. (1): 


$$
X_{i j}=\frac{C_{i j}}{\sum C_{i j}},
$$

where

$C_{i \mathrm{j}} \quad$ criteria value;

$\sum C_{i j}$ column sum.

Calculate priority vector from Eq. (2):

$$
W_{i j}=\frac{\sum X_{i j}}{n},
$$

where

$\sum X_{i j}$ normalized matrix column sum;

$n \quad$ number of criteria.

In application of this AHP method to calculate weight it is important to use experts to evaluate criteria because this affects the alternative's values in the future when MCDA methods are using criteria weight.

When weights are calculated using the AHP method, these values can be used in every MCDA method. Also, after the AHP method, results can make conclusions about the indicated values and which indicator can solve the problem.

\subsection{TOPSIS}

The full name of the method is Technique for Order Preference by Similarity to Ideal Solutions. This method evaluates the distance of alternatives to ideal and anti-ideal point and alternative with shortest distance to ideal point is the best alternative. There are three distances in the TOPSIS method - Manhattan distance, Tchebycheff distance and Euclidean distance, which were all used in this study Eq. (1).

TOPSIS method Eq. (3), (4), (5), (6) and (7) are from [3]. Method described:

- Calculate normalized matrix using Eq. (3):

$$
R=\frac{X}{\sqrt{\sum X^{2}}},
$$

where

$X \quad$ criteria value;

$\sum X \quad$ sum of criteria value.

- Calculate normalized weight matrix from Eq. (4):

$$
V=R \times W \text {, }
$$

where

$R \quad$ normalized matrix value;

$W \quad$ criteria weight.

- Define the best and worst values of criteria: best values $\mathrm{V}^{+}=\max$ and worst values $\mathrm{V}^{-}=\min$; best values $\mathrm{V}^{+}=\min$ and worst values $\mathrm{V}^{-}=\max$. 
- Use of formulas as shown in Eq. (5) and (6) to difference value from best or worst value:

$$
d_{a}^{+}=\sqrt{\sum\left(V^{+}-v_{a}^{2}\right)^{2}}
$$

where

$V^{+}$ideal or best value;

$v_{a}$ normalized weighted matrix value,

$$
d_{a}^{-}=\sqrt{\sum\left(V^{-}-v_{a}^{2}\right)^{2}}
$$

where

$V^{-} \quad$ non-ideal or worst value;

$v_{a} \quad$ normalized weighted matrix value.

- Find the relative closeness and rank the alternatives using Eq. (7):

$$
C_{a}=\frac{d_{a}^{-}}{d_{a}^{+}-d_{a}^{-}},
$$

where

$d_{a} \quad$ non-ideal or worst value;

$d^{+}{ }_{a} \quad$ ideal or best value.

The main difference between this and other methods is that TOPSIS uses best and worst value for each criterion and calculates the value of alternatives using gap between best and worst criteria. The smallest difference between best and worst values are the closer values for results of alternatives will be.

\subsection{VIKOR}

The full name of the method in Serbian is VlseKriterijumskaOptimizacija I KompromisnoResenj. In this method, an important factor is alternative closeness to the ideal solution and after that alternatives are ranked [13]. The Euclidean distance[14] is used in this method.

Eq. (8) and Eq. (9) are from [26]. Method described:

- Define best and worst value of criteria.

- Find values for best and worst values matrix using Eq. (8):

$$
S=w \frac{f^{*}-f}{f^{*}-f^{-}},
$$

where

w criteria weight;

$f \quad$ criteria value;

$f^{*} \quad$ best value of criteria (max or $\left.\min \right)$;

$f \quad$ worst value of criteria (min or max).

- Find values $S, R$ and $Q$ for each alternative: 


$$
Q=v \frac{S_{j}-S^{*}}{S^{-}-S^{*}}+(1-v) \frac{R_{j}-R^{*}}{R^{-}-R^{*}}
$$

where $v$ is decision making factor (if major agreement than $v \geq 0.5$, if consensual agreement than $v=0.5$, if agreement with veto than $v \leq 0.5$ ), in this case $v=0.5$;

$S_{j}=\sum w \frac{f^{*}-f_{i}}{f^{*}-f^{-}}, S^{*}=\min S_{j}, S^{-}=\max S_{j} ; R j=\max \left[w \frac{f^{*}-f_{i}}{f^{*}-f^{-}}\right], R^{*}=\min R_{j}, R^{-}=\max R_{j}$.

In this method, there is not a normalized and normalized weights matrix as in the TOPSIS, COPRAS and MULTIMOORA methods.

\subsection{COPRAS}

The full name of the method is Complex Proportional Assessment. This method applies stepwise sorting and utility degree calculation which helps when there are conflicting criteria [4]. In order to achieve alternative sequencing after utility degree, the alternatives needs to be sorted in descending order [5].

The COPRAS method equations (10), (11), (12), (13), (14) and (15) are from [15].

Method described:

- Find normalized matrix from Eq. (10):

$$
\overline{x_{i j}}=\frac{x_{i j}}{\sum x_{i j}}
$$

where

$x_{i j} \quad$ criteria values;

$\sum x_{i j} \quad$ sum of criteria values.

- Find normalized weighted matrix from Eq. (11):

$$
\widehat{x_{i j}}=\overline{x_{i j}} \times w,
$$

where

$\overline{x_{i j}} \quad$ normalized matrix values;

$w \quad$ criteria weight.

- Determination of the maximizing index Eq. (12) and minimizing index Eq. (13):

$$
\begin{aligned}
& P_{j}=\sum \widehat{x_{i j}}, \\
& R_{j}=\sum \widehat{x_{i j}},
\end{aligned}
$$

where

$P_{j} \quad$ maximizing index;

$R_{j} \quad$ minimizing index;

$\widehat{x_{i j}} \quad$ weighted normalized matrix. 
- Using Eq. (14) find relative weights for every alternative:

$$
Q_{j}=P_{j}+\frac{\sum R_{j}}{R_{j} \sum \frac{1}{R_{j}}},
$$

where

$P_{j} \quad$ maximizing index;

$R_{j} \quad$ minimizing index.

- Calculate utility degree using Eq. (15):

$$
N=\frac{Q i}{Q_{\max }} \times 100 \% .
$$

In this method criteria value and all alternative sums are used to find values of normalized matrix, but in other methods, like TOPSIS, the criteria value and square root from sum of square is used to calculate values of alternatives.

\subsection{MULTIMOORA}

Full name of method is Multi-Objective Optimization on the basis of Ratio Analysis.

MULTIMOORA is a system that optimizes conflicting alternatives to find the best result and is easy to apply to solve various problems [5].This method has an extended version where it is possible to work with a value interval [16].

Equations (16), (17), (18) and (19) for MULTIMOORA method are from [17]. Method described:

- Normalized matrix in Eq. (16):

$$
X^{*}=\frac{x_{i}}{\sqrt{\sum x_{i}^{2}}},
$$

where $x_{i}$ is criteria value.

- Calculate normalized weight matrix using Eq. (17):

$$
Y=x_{i} \times w,
$$

where:

$x_{i} \quad$ normalized matric value;

$w$ criteria weight.

- Difference between max and min values for each alternative using Eq. (18):

$$
y_{i}=\sum \max x_{i j}^{*}-\sum \min x_{i j}^{*} .
$$

- Find alternatives values from Eq. (19):

$$
U_{i}=\frac{\sum \max X_{i j}^{*}}{\sum \min X_{i j}^{*}} .
$$


In this method, it is possible to use inverse formula of Eq. (19) and use the minimum value as the best alternative, if it is needed to compare with other methods where minimum values are the best alternatives as in case of the VIKOR method.

In this method it is quite important to calculate the difference between minimum and maximum values of criteria and the value of alternative

\subsection{PROMETHEE-GAIA}

PROMETHEE stands for Preference Ranking Organization Method for the Enrichment of Evaluations and GAIA stands for Graphical Analysis for Interactive Aid [30].

In the PROMETHEE method, criteria weight gives more impact than the values of the preference function threshold [30]. It is possible to choose preference functions and software can be used to arrange the criteria and their weights [30]. Calculations are made in the program Visual PROMETHEE academic.

\section{RESUlTS AND DISCUSSION}

The AHP method pairwise comparison is made by assessing the importance of the criterion over the other criterion and the results are illustrated in Table 3. In pair comparison value 1 represents that both criteria are equally important, value 5 represents that one criterion is very important compared to other criteria and value 9 represents that one criterion is absolutely most important than other criteria. And for opposed criteria comparison values are proportionally opposed. This pairwise comparison was made by three experts from the field of environmental science.

After calculation criteria weight very important is to verify if $\sum W_{i j}=1$ and consistency values, for this AHP consistency index (CI) is 0.127 and consistency ratio (CR) is 0.097 . If $\mathrm{CR}>10 \%$ then pairwise comparisons are inconsistent [2].

Table 4 contains all criteria and their weights. The most important criteria are installed electrical capacity with a weight $27 \%$ and the next is job creation criteria with $22 \%$ weight. The lowest impact on alternatives is from the criteria about levelled cost of electricity and on life-cycle $\mathrm{CO}_{2}$ emissions.

Important value in the TOPSIS method is alternative closeness indicator which are final value for alternative and are in Table 5. Based on the results of the TOPSIS method, the best alternative is the hydroelectric power plant (HPP) followed by biomass and biogas CHP (Bio-energy CHP).

In accordance with the VIKOR method, the best alternative is that with the minimal value. Results of this method are in Table 6 and the best alternative is hydroelectric power plant (HPP) then solar PV. To compare VIKOR and other methods it is important to remember that in this method an important step is to minimize all criteria to make comparisons.

The COPRAS method is simple and most impact for best alternative is from criteria weight and index values. Based on this method, the best alternative is solar photovoltaic (Solar PV) and hydroelectric power plant (HPP). The values of alternatives are presented in Table 7. Best alternative in this method is Solar PV and worst alternative is wind power plants (WPP) and both alternatives have large difference in their final values and this might be because of these alternative values for each criterion. 


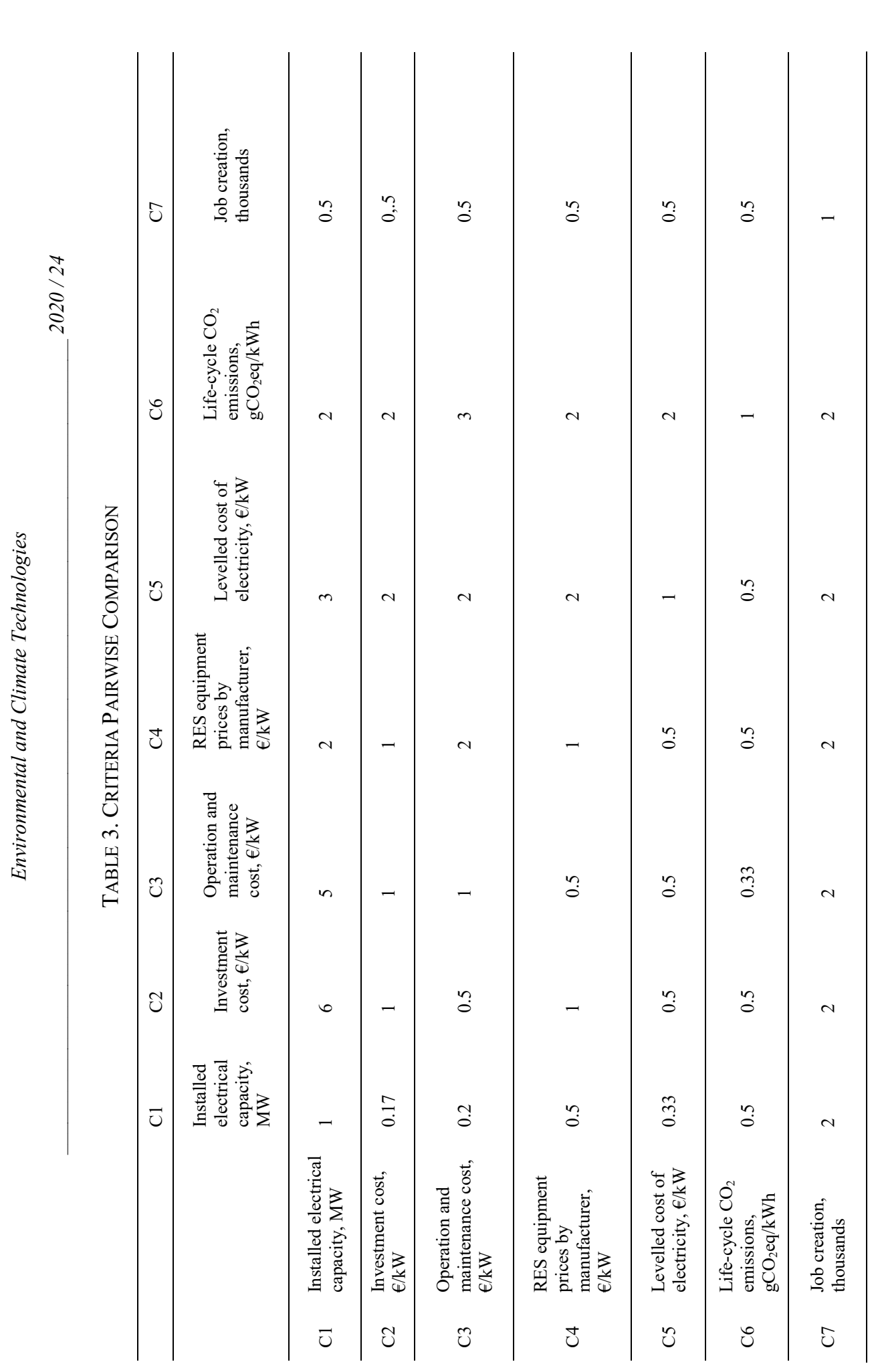




\section{TABLE 4. CRITERIA VALUES AND WEIGHTS}

\begin{tabular}{ll}
\hline Installed electrical capacity, $\mathrm{MW}$ & $27 \%$ \\
Investment cost, $€ / \mathrm{kW}$ & $12 \%$ \\
Operation and maintenance cost, $€ / \mathrm{kW}$ & $13 \%$ \\
RES equipment prices by manufacturer, $€ / \mathrm{kW}$ & $11 \%$ \\
Levelled cost of electricity, $€ / \mathrm{kW}$ & $8 \%$ \\
Life-cycle $\mathrm{CO}_{2}$ emissions, $\mathrm{gCO}_{2} \mathrm{eq} / \mathrm{kWh}$ & $7 \%$ \\
Job creation, thousands & $22 \%$ \\
\hline
\end{tabular}

TABLE 5. TOPSIS RESULT AND RANK

\begin{tabular}{llll}
\hline A1 & A2 & A3 & A4 \\
Solar PV & WPP & HPP & Bio-energy CHP \\
0.33 & 0.16 & 0.77 & 0.28 \\
2 & 4 & 1 & 3 \\
\hline
\end{tabular}

TABLE 6. VIKOR RESULTS AND RANK

\begin{tabular}{llll}
\hline A1 & A2 & A3 & A4 \\
Solar PV & WPP & HPP & Bio-energy CHP \\
0.67 & 0.92 & 0 & 0.81 \\
2 & 3 & 1 & 4 \\
\hline
\end{tabular}

TABLE 7. COPRAS RESULTS AND RANK

\begin{tabular}{llll}
\hline A1 & A2 & A3 & A4 \\
Solar PV & WPP & HPP & Bio-energy CHP \\
1.94 & 0.86 & 1.47 & 0.93 \\
1 & 4 & 2 & 3 \\
\hline
\end{tabular}

Results from the MULTIMOORA method is in Table 8 and the best alternative is solar photovoltaic (Solar PV) and hydroelectric power plant (HPP). Final values have large range and it's because final values are calculated from difference between the minimum and maximum values

TABLE 8. MULTIMOORA RESULTS AND RANK

\begin{tabular}{llll}
\hline A1 & A2 & A3 & A4 \\
Solar PV & WPP & HPP & Bio-energy CHP \\
3.25 & 0.47 & 1.93 & 0.28 \\
1 & 3 & 2 & 4 \\
\hline
\end{tabular}

Table 9 contains results from the PROMETHEE-GAIA method and the complete ranking is based on net preference flow (Phi) which is a balance between positive preference flow (Phi + ) which 
measures strength and negative preference flow ( $\left.\mathrm{Phi}^{-}\right)$that represents weakness. In this case, the preference function is linear and thresholds are absolute. In accordance with this method, the best alternative is the hydroelectric power plant (HPP) and solar photovoltaic (Solar PV).

TABLE 9. COMPLETE RANKING

\begin{tabular}{lllll}
\hline & A1 & A2 & A3 & A4 \\
& Solar PV & WPP & HPP & Bio-energy CHP \\
Phi & 0.0100 & -0.2567 & 0.2833 & -0.0367 \\
Phi + & 0.4533 & 0.3200 & 0.5900 & 0.4300 \\
Phi- $^{-}$ & 0.4433 & 0.5767 & 0.3067 & 0.4667 \\
\hline
\end{tabular}

PROMETHEE rankings results can be displayed as PROMETHEE Diamond in Fig. 1. In the PROMETHEE Diamond, each alternative has point on the $\left(\mathrm{Phi}^{+}, \mathrm{Phi}^{-}\right)$plane and the vertical dimension (green-red axis) corresponds to the Phi net flow which is a balance point [18].

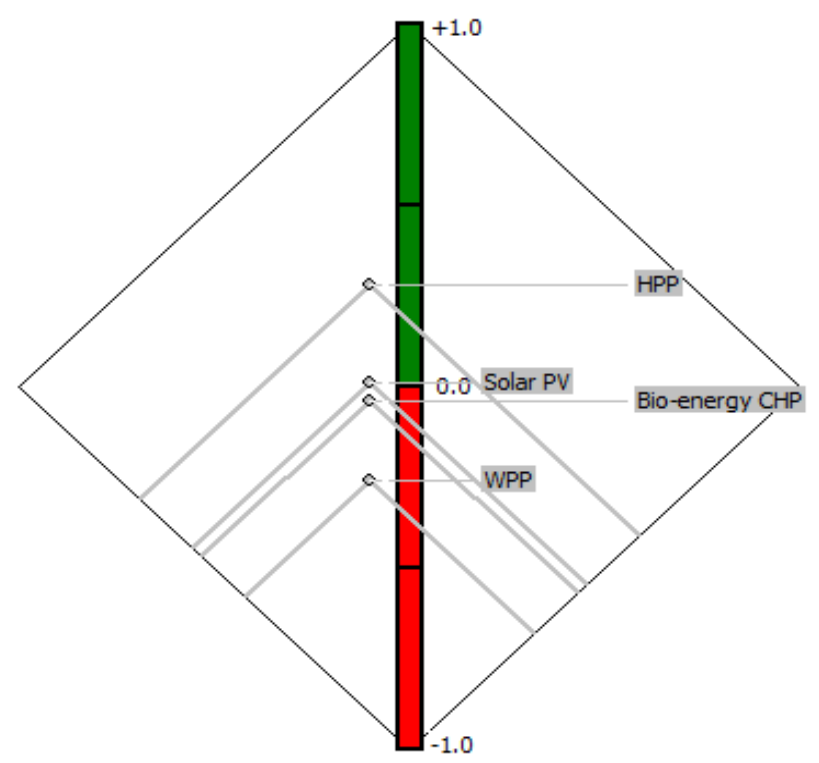

Fig. 1. PROMETHEE Diamond.

Fig. 2 illustrates the PROMETHEE Network and shows which alternative is better and helps to compare alternatives. The network representation is like a close-up of the Diamond view where the distances between the alternatives are displayed [30]. 


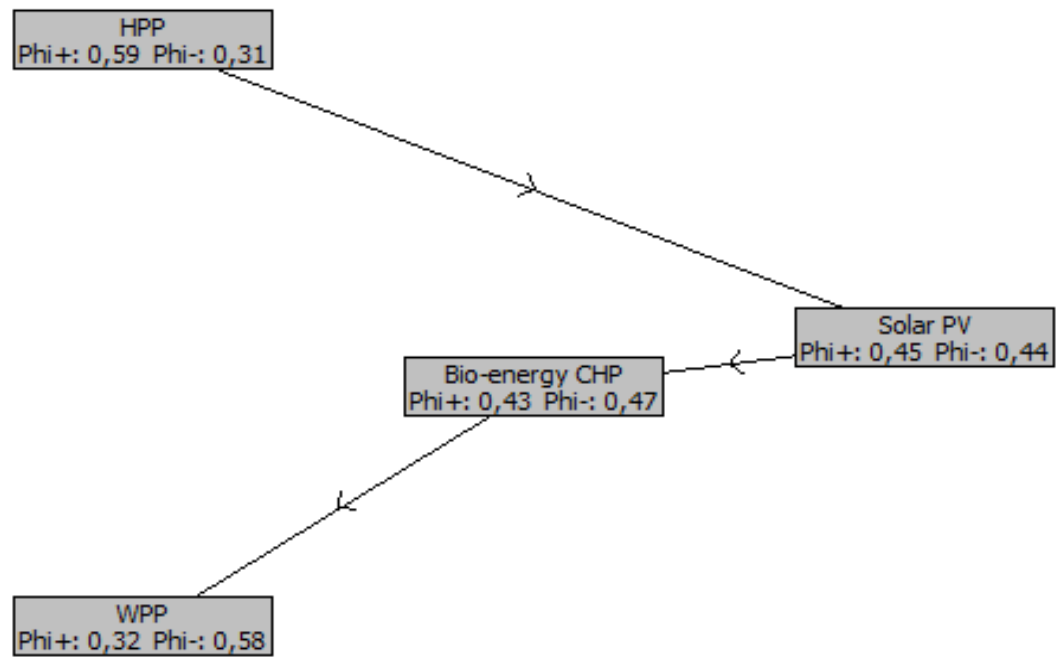

Fig. 2. PROMETHEE Network.

The PROMETHEE Rainbow is shown in Fig. 3 where every alternative's strong and weak criterion is depicted. Positive (upward) slices represents criteria that positively affects the alternative and negative (downward) slices represent criteria that give a negative effect to the alternative [18].

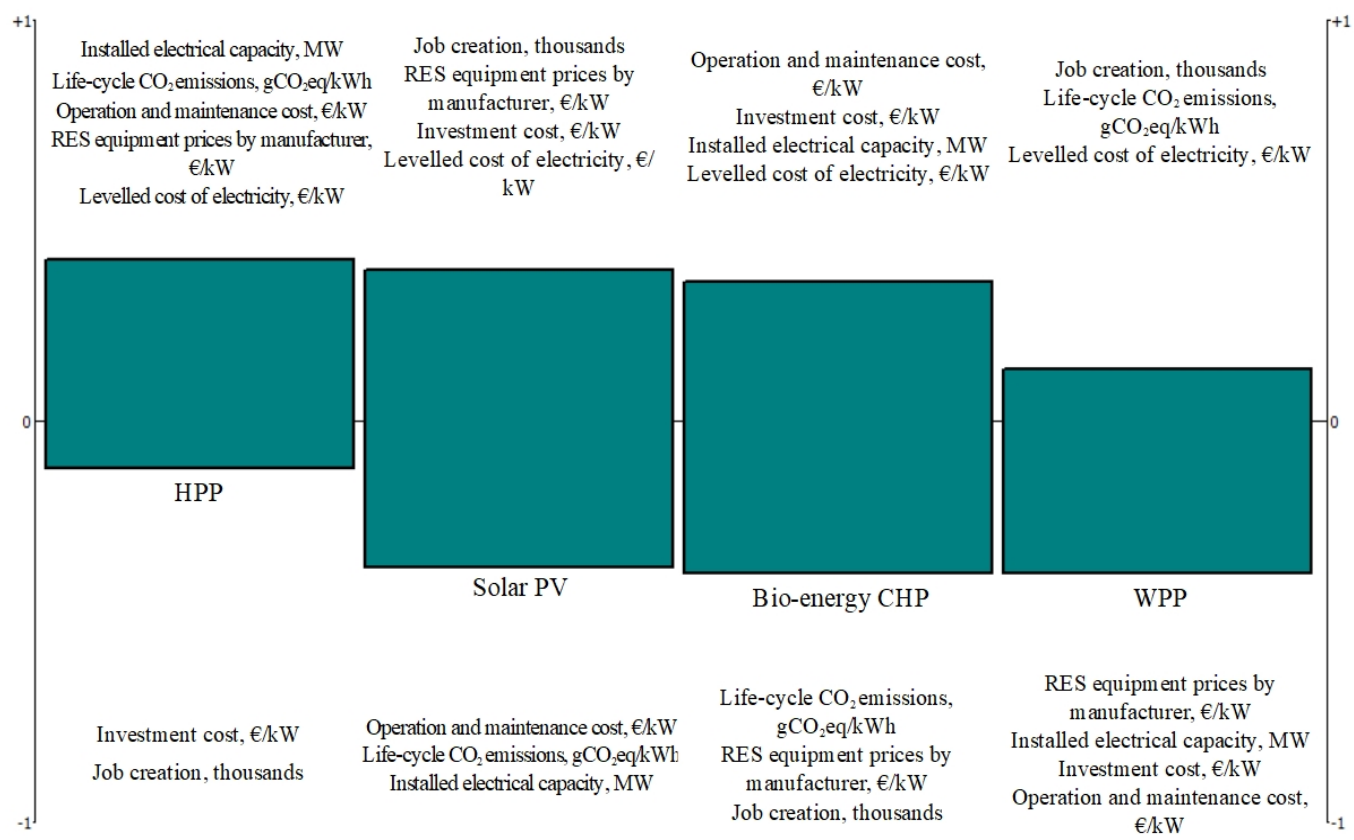

Fig. 3. PROMETHEE Rainbow. 
For the hydroelectric power plant (HPP) alternative, weakness stems from investment cost and job creation and after this method it is the best alternative. For wind power plants (WPP) which are the worst alternative, there are only three good criteria - job creation, life-cycle $\mathrm{CO}_{2}$ emissions and levelled cost of electricity.

After five Multi-criteria decision analyses - TOPSIS, VIKOR, MULTIMOORA, COPRAS and PROMETHEE-GAIA, Table 10 provides a summary of all final values for each alternative. For TOPSIS, VIKOR and PROMETHEE-GAIA methods the best alternative is hydroelectric power plant (HPP) and in accordance with the other 2 methods, HPP is ranked second. But in COPRAS and MULTIMOORA methods, the best alternative is solar photovoltaic (Solar PV). The most impact for the final results is from criteria weights and methods definition of best alternative closeness indicator to ideal distance, closeness score to best option, pairwise outranking or ranking with scores. The best value of the criteria - minimum or maximum - is also an important indicator.

TABLE 10. Alternative VALUES AND RANKING

\begin{tabular}{lllll}
\hline & Solar PV & WPP & HPP & Bio-energy CHP \\
\hline TOPSIS & 0.33 & 0.16 & 0.77 & 0.28 \\
& 2 & 4 & 1 & 3 \\
\hline VIKOR & $\mathbf{0 . 6 7}$ & $\mathbf{0 . 9 2}$ & $\mathbf{0}$ & $\mathbf{0 . 8 1}$ \\
& 2 & 3 & 1 & 4 \\
\hline COPRAS & $\mathbf{1 . 9 4}$ & $\mathbf{0 . 8 6}$ & $\mathbf{1 . 4 7}$ & $\mathbf{0 . 9 3}$ \\
& 1 & 4 & 2 & 3 \\
\hline PROTIMOORA & 3.25 & 0.47 & $\mathbf{1 . 9 3}$ & $\mathbf{0 . 2 8}$ \\
& 1 & 3 & 2 & 4 \\
\hline
\end{tabular}

The results from MCDA methods are reflected in Fig. 4 and they are ranked from best to worst alternative. After this result is displayed in the diagram, it is easier to see the trend in terms of which alternatives are ranked higher than others. The best alternative would be hydroelectric power plant (HPP) and then solar photovoltaic (Solar PV) because these alternatives are in first or second position in comparison with most of the other alternatives.

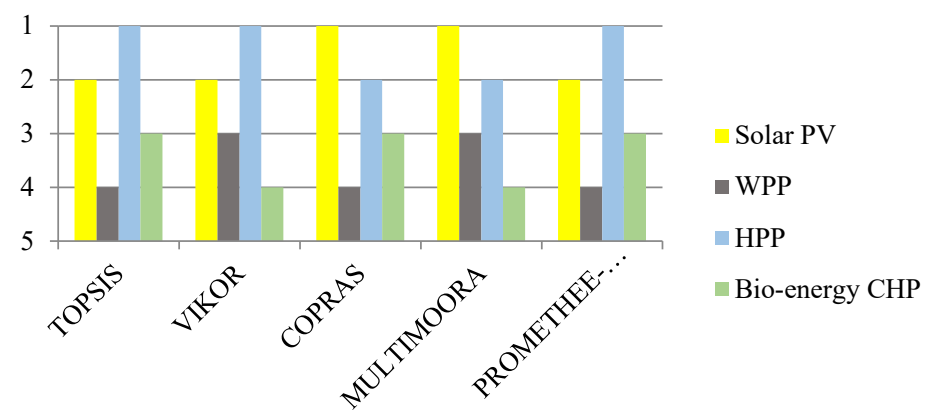

Fig. 4. Result rank of MCDA methods. 
The lowest rank is for the wind power plants (WPP) alternative because in 3 out of 5 methods it is in the last place. For this alternative minimal and maximal criterion values are lowest rates which impact final ranking.

\section{Conclusion}

The aim of this paper was to use same input data for five MCDA methods and to see if alternatives ranking would be the same or different for each method and of course to see which is the best renewable energy technology for Latvia. Five MCDA methods - TOPSIS, VIKOR, COPRAS, MULTIMOORA and PROMETHEE GAIA have been chosen because they have different approaches on how to calculate alternatives values and there it was possible to use criteria which can be definite minimum or maximum as best value.

The same results were not obtained for all methods but in all methods two alternatives were in the first two places as best alternatives - hydroelectric power plant (HPP) and solar photovoltaic (Solar PV). On the basis of seven criteria, the best renewable energy technology for Latvia is hydroelectric power plant (HPP) and it is because in the most valuable criteria installed electrical capacity $(27 \%)$ in this alternative had best results from all energy alternatives.

The results of five MCDA methods have produced different results, but with a similar trend to best alternative. It's not really objective to compare the results obtained by different methods because results are similar but not the same. To get more reliable results and for comparison use one methodology for problem and sub-problem. MCDA methods are developing with new modules and software's which are more specific and helpful to solve problems. Methods can be chosen after goal of result, method approach, input and output type, used software and suitability for the problem.

\section{ACKNOWLEDGEMENT}

The research is funded by the Ministry of Economics of the Republic of Latvia, project "Assessment of Latvia's renewable energy supply-demand economic potential and policy recommendations”, Project No. VPP-EM-2018/AER-1-000.

\section{REFERENCES}

[1] Langemeyer J., Gomez-Baggethun E., Haase D., Scheuer S., Elmqvist T. Bridging the gap between ecosystem service assessments and land-use planning through Multi-Criteria Decision Analysis (MCDA). Environmental Science \& Policy 2016:62:45-56. https://doi.org/10.1016/j.envsci.2016.02.013

[2] Ishizaka A., Nemery P. Multi-Criteria Decision Analysis. John Wiley \& Sons, 2013.

[3] Yazdani M., Payam A. F. A comparative study on material selection of microelectromechanical systems electrostatic actuators using Ashby, VIKOR and TOPSIS. Materials \& Design 2015:65:328-334. https://doi.org/10.1016/j.matdes.2014.09.004

[4] Debbarma B., Chakraborti P., Bose P. K., Deb M., Banerjee R. Exploration of PROMETHEE II and VIKOR methodology in a MCDM approach for ascertaining the optimal performance-emission trade-off vantage in a hydrogenbiohol dual fuel endeavour. Fuel 2017:210:922-935. https://doi.org/10.1016/j.fuel.2017.08.016

[5] Chen Y., Ran Y., Wang Z., Li X., Yang X., Zhang G. An extended MULTIMOORA method based on OWGA operator and Choquet integral for risk prioritization identification of failure modes. Engineering Applications of Artificial Intelligence 2020:91:103605. https://doi.org/10.1016/j.engappai.2020.103605

[6] Obayiuwana E., Falowo O. A multimoora approach to access network selection process in heterogeneous wireless networks. IEEE AFRICON Conf. 2015. https://doi.org/10.1109/AFRCON.2015.7331973.

[7] Sennaroglu B., Varlik Celebi G. A military airport location selection by AHP integrated PROMETHEE and VIKOR methods. Transportation Research Part D: Transport and Environment 2018:59:160-173.

https://doi.org/10.1016/j.trd.2017.12.022 
[8] Garg R., Jain D. Fuzzy multi-attribute decision making evaluation of e-learning websites using FAHP, COPRAS, VIKOR, WDBA. Decision Science Letters 2017:6(4):351-364. https://doi.org/10.5267/j.ds1.2017.2.003.

[9] Fakhrehosseini S. F. Selecting the Optimal Industrial Investment by Multi-Criteria Decision-Making Methods with Emphasis on TOPSIS, VIKOR and COPRAS (Case Study of Guilan Province). International Journal of Research in Industrial Engineering 2020:8(4):312-324. https://doi.org/10.22105/riej.2020.216548.1117

[10] Batur Sir G. D., Çalışkan E. Assessment of development regions for financial support allocation with fuzzy decision making: A case of Turkey. Socio-Economic Planning Sciences 2019:66:161-169. https://doi.org/10.1016/j.seps.2019.02.005

[11] Leal J. E. AHP-express : A simplified version of the analytical hierarchy process method. MethodsX 2020:7:100748. https://doi.org/10.1016/j.mex.2019.11.021

[12] Opricovic S. Compromise solution by MCDM methods: A comparative analysis of VIKOR and TOPSIS. 2004:156(2):445-455. https://doi.org/10.1016/S0377-2217(03)00020-1

[13] Chatterjee P., Manikrao V., Chakraborty S. Materials selection using complex proportional assessment and evaluation of mixed data methods. Materials \& Designs 2011:32(2):851-860. https://doi.org/10.1016/j.matdes.2010.07.010

[14] Ajrina A. S., Sarno R., Hari Ginardi R. V. Comparison of MOORA and COPRAS Methods Based on Geographic Information System For Determining Potential Zone of Pasir Batu Mining. International Conference on Information and Communications Technology, ICOIACT 2019:360-365. https://doi.org/10.1109/ICOIACT46704.2019.8938465

[15] Suharevska, K., Blumberga, D. Progress in Renewable Energy Technologies: Innovation Potential in Latvia. Environmental and Climate Technologies 2019:23(2):47-63. https://doi.org/10.2478/rtuect-2019-0054

[16] Whiteman, A., Sohn, H., Esparrago, J., Arkhipova, I., and Elsayed S. Renewable Capacity Statistics. IRENA, 2018. [Online]. [Accessed: April 7, 2020]. Available: https://www.irena.org//media/Files/IRENA/Agency/Publication/2018/Mar/IRENA_RE_Capacity_Statistics_2018.pdf

[17] A. Ilas, P. Ralon, A. Rodriguez, and M. Taylor. Renewable Power Generation Costs in 2018. International Renewable Energy Agency, IRENA, 2018. [Online]. [Accessed: April 8, 2020]. Available: https://www.irena.org/publications/2019/May/Renewable-power-generation-costs-in-2018

[18] US Energy Information Administration. Levelized Cost and Levelized Avoided Cost of New Generation Resources. Annual Energy Outlook 2019. [Online]. [Accessed: April 8, 2020]. Available: http://www.eia.gov/forecasts/aeo/pdf/electricity_generation.pdf.

[19] European Environment Agency. Renewable Energy in Europe - 2017 Update. EEA Report, No. 23/2017 [Online]. [Accessed: April 7, 2020]. Available: https://www.eea.europa.eu//publications/renewable-energy-in-europe

[20] World Nuclear Association. Comparison of Lifecycle Greenhouse Gas Emissions of Various Electricity Generation Sources. WNA Report, 2011. [Online]. [Accessed: April 7, 2020]. Available: http://www.worldnuclear.org/uploadedFiles/org/WNA/Publications/Working_Group_Reports/comparison_of_lifecycle.pdf

[21] Ferroukhi, R., Khalid, A., García-Baños, C., and Renner, M. Renewable Energy and Jobs - Annual Review 2017. IRENA, 2017. [Online]. [Accessed: April 8, 2020]. Available: https://www.irena.org/publications/2017/May/Renewable-Energy-and-Jobs--Annual-Review-2017

[22] Saaty T. L., Ozdemir M. S. Why the magic number seven plus or minus two. Mathematical and Computer Modelling 2003:38(3-4):233-244. https://doi.org/10.1016/S0895-7177(03)90083-5

[23] Kablan M. M. Decision support for energy conservation promotion: An analytic hierarchy process approach. Energy Policy 2004:32(10):1151-1158. https://doi.org/10.1016/S0301-4215(03)00078-8

[24] Opricovic S. Extended VIKOR method in comparison with outranking methods. European Journal of Operational Research 2007:178:514-529. https://doi.org/10.1016/j.ejor.2006.01.020

[25] Hafezalkotob A., Hafezalkotob A. Interval target-based VIKOR method supported on interval distance and preference degree for machine selection. Engineering Applications of Artificial Intelligence 2017:57:184-196. https://doi.org/10.1016/j.engappai.2016.10.018

[26] Sayadi M. K., Heydari M., Shahanaghi K. Extension of VIKOR method for decision making problem with interval numbers. Applied Mathematical Modelling 2009:33(5):2257-2262. https://doi.org/10.1016/j.apm.2008.06.002

[27] Nuuter T., Lill I., Tupenaite L. Land Use Policy Comparison of housing market sustainability in European countries based on multiple criteria assessment. Land Use Policy 2015:42:642-651. https://doi.org/10.1016/j.landusepol.2014.09.022

[28] Hafezalkotob A., Hafezalkotob A., Kazem M. Extension of MULTIMOORA method with interval numbers: An application in materials selection. Applied Mathematical Modelling 2016:40(2):1372-1386. https://doi.org/10.1016/j.apm.2015.07.019

[29] Karande P., Chakraborty S. Application of multi-objective optimization on the basis of ratio analysis (MOORA) method for materials selection. Materials \& Design 2012:37:317-324. https://doi.org/10.1016/j.matdes.2012.01.013

[30] Mareschal, B. Visual PROMETHEE 1.4 Manual. VPSolutions 2012-2013:1-192. [Online]. [Accessed: April 9 , 2020]. Available: http://www.promethee-gaia.net/files/VPManual.pdf 


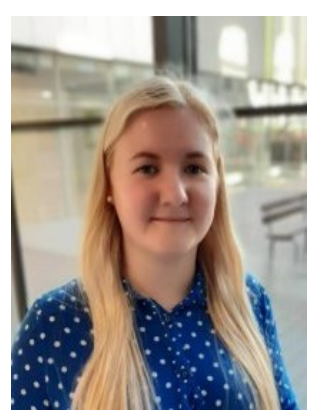

Beate Zlaugotne, M. sc. ing. student, research assistant at RTU Institute of Energy Systems and Environment (IESE). The main areas of research are the analysis of multi-criteria decisions and the use of renewable energy sources and their alternatives.

E-mail: Beate.Zlaugotne@,rtu.lv

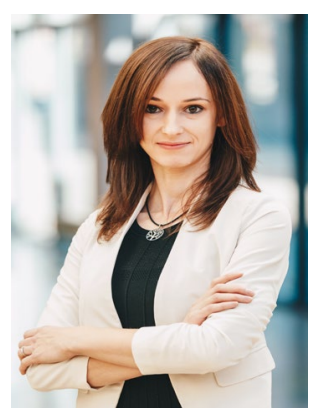

Lauma Zihare, M. sc., Riga Technical University, Institute of Energy Systems and Environment. Lauma Zihare acquired Bachelor's degree of Social sciences in Management in 2011 at University of Latvia and Master's degree in Environmental Science in 2016 at Riga Technical University.

She has continuous working experience as a researcher in Riga Technical University. Currently she is a $\mathrm{PhD}$ candidate at Institute of Energy Systems and Environment. The main research areas are bioeconomy, bioresources and sustainability.

E-mail: Lauma.Zihare@rtu.lv

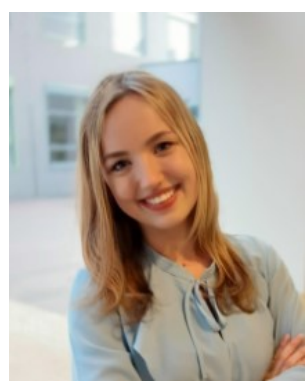

Lauma Balode, M. sc. ing. student at Riga Technical University in the field of Environmental Engineering. Lauma Balode is currently working at Riga Technical University in the Institute of Energy Systems and Environment as a research assistant.

She has previously (2017) received Master's degree in Environmental Science of Latvian University Faculty of Geography and Earth Sciences.

Her work field is related to the use of renewable energy sources.

E-mail: Lauma.Balode@rtu.lv

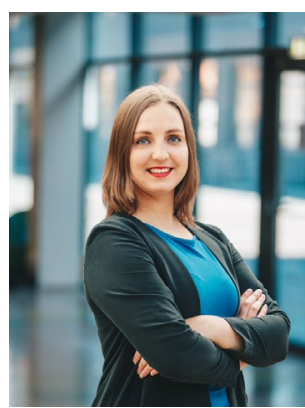

Antra Kalnbalkite has received M. sc. degree from Riga Technical University (RTU) in 2017. She is on her 1st year of PhD studies in Environmental Engineering, RTU. Author is working at Riga Technical University in the Institute of Energy Systems and Environment as a Researcher. Current research is related to sustainable environmental engineering education. E-mail: Antra.Kalnbalkite@rtu.lv 


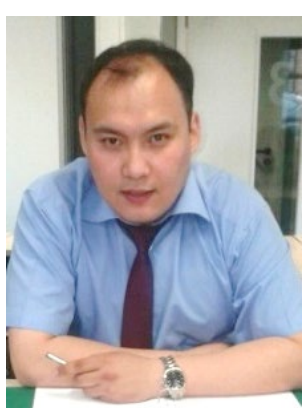

E-mail: aset85@mail.ru

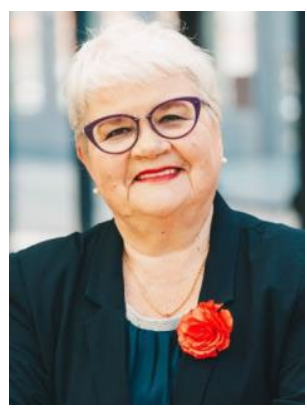

Aset Khabdullin, graduated specialty Electricity by Industry and enrolled in full-time training in Moscow Power Engineering Institute (Technical University) in 2007. In 2012 he defended his thesis for the degree of Candidate of Technical Sciences, specialty 05.09.03 Electrical Equipment and Systems.

He worked as a lecturer and as a senior lecturer for "Power and Electrification" in Rudny Industrial Institute, Republic of Kazakhstan. Currently he is the Dean of the Faculty "Energy and Information Systems" at Rudny Industrial Institute.

He published scientific articles in the leading academic and technical journals in the Czech Republic, Bulgaria and Turkey, and presented also at international conferences, meetings and online conferences. He has more than 40 scientific publications and scholarly materials, direct scientific - research work of students. He develops projects for energy direction for enterprises of the Northern region of Kazakhstan, examines scientific competitive projects MES RK and enterprises, and conducts counselling for the employees of enterprises.

Dagnija Blumberga, Dr. habil. sc. ing., professor, director of the Institute of Energy Systems and Environment, Riga Technical University. Her two-step doctoral degree "Condensing Unit" was defended in Lithuanian Energy Institute, Kaunas (1988). Doctor Habilitus Thesis "Analysis of Energy Efficiency from Environmental, Economical and Management Aspects" was prepared in Royal Institute of Technology (KTH) Stockholm (1995) and was defended in Riga Technical University (1996).

Dagnija Blumberga has been part of academic staff of Riga Technical University since 1976 and director of Institute of Environmental Protection and Energy Systems since 1999.

The main research area is renewable energy resources. She has participated in different local and international projects related to energy and environment as well as an author of more than 200 publications and 14 books.

ORCID ID: https://orcid.org/0000-0002-9712-0804

E-mail: Dagnija.Blumberga@rtu.lv 